\title{
Acoustic Attenuation Performance of Two-Pass Perforated Hybrid Mufflers with Mean Flow
}

\author{
Yiliang Fan and Zhenlin Ji \\ Harbin Engineering University, Harbin, Heilongjiang, 150001, P.R. China. E-mail: jizhenlin@ hrbeu.edu.cn
}

\begin{abstract}
(Received 29 April 2021; accepted 20 August 2021)
The one-dimensional (1-D) analytical approach is developed to predict and analyze the acoustic attenuation performance of two-pass perforated hybrid mufflers in the presence of mean flow. The expressions of complex acoustic wavenumber and impedance of long fiber glass wool are presented by using the impedance tube measurement and curve fitting. The 1-D approaches as well as the fitting expressions are validated by comparing the predicted and measured transmission loss of two-pass perforated hybrid mufflers with a different Mach number. Results illustrate that the 1-D predictions agree well with measurements below the plane wave cut-off frequency and deviate in higher frequency range. The influences of geometric parameters including the lengths of extended tubes, perforations on the right bulkhead and the outlet tube, and mean flow on the acoustic attenuation behavior of the hybrid mufflers are examined.
\end{abstract}

\section{INTRODUCTION}

Hybrid mufflers may provide high acoustic attenuation over wide frequency range, and are extensively used to attenuate the noise generated by internal combustion engines, blowers and fans. Perforated components may enhance the acoustic attenuation, reduce the pressure drop and protect the soundabsorbing material from the air flow, hence they are widely used in mufflers. The prediction of acoustic attenuation performance of muffler containing perforated components has been a topic of interest for many years.

Peat presented the numerical decoupling approach to extract eigenvalues and eigenvector and obtained the transfer matrix of the straight-through perforated tube muffler. ${ }^{1}$ Gogate and Munjal presented transfer matrices of the two-pass and threepass perforated tube mufflers. ${ }^{2,3}$ Selamet et al. applied the transfer matrix method by using numerical decoupling to predict and analyze the acoustic attenuation performance of threepass mufflers with uniform perforated elements. ${ }^{4}$ Fan and Ji investigated the impact of perforations on inlet and outlet tubes on the acoustic attenuation performance of three-pass perforated tube mufflers by the 1-D analytical approach, which was validated by comparing the predicted and measured transmission loss. ${ }^{5}$ Dickey presented a 1-D time-domain approach to predict the transmission loss of single and multiple pass perforated tube mufflers; the approach was verified by comparing transmission loss predictions and measurements in the absence of mean flow. ${ }^{6}$ Ramya and Munjal presented endcorrection expressions for the higher-order modes generated at the perforated-chamber interface to analyze the acoustic behavior of the extended concentric tube resonator. ${ }^{7}$ The multipass muffler configurations often have short end-chambers, which serve as a resonator and provides attenuation peak in the low-frequency range. The sound propagations in the short chambers have been explicitly addressed by Mimani, Selamet and Ji as well as Selamet and Denia and may be adopted for mufflers with short end-chambers. ${ }^{8-10}$ For these typical mufflers, the 1-D predictions agree well with measurements in the plane wave range. Beyond the plane wave cut-off frequency the 1-D approaches are less suitable since the effects of a multi-dimensional wave may not be negligible. In order to predict the acoustic attenuation performance in the high frequency range, three-dimensional (3-D) numerical methods like finite element method (FEM) and boundary element method (BEM) are needed. Ji and Fang developed the 1-D analytical approach, FEM and BEM to predict the acoustic attenuation characteristics of the three-pass perforated tube muffler with end-resonator and indicated that results from FEM and BEM agree well with each other in the whole frequency range of interest, while the 1-D solutions show reasonable agreement with 3 -D predictions below the plane wave cut-off frequency. ${ }^{11}$

In practical applications, the air flow imparts convective and dissipative effects on sound propagation, which may impact the acoustic attenuation behavior of mufflers. The convective effects mainly impact the resonance and pass frequencies and may be captured by the convective wave equation. The dissipative effects of perforated sections may be considered by adopting appropriate acoustic impedance expressions of perforation. Torregrosa et al. proposed a simple flow model to assess the influences of mean flow and dissipation on the acoustic performance of the classical two-duct Herschel-Quincke tube; the model included the transfer matrix for the system and algorithms for estimating Mach number. ${ }^{12}$ Kirby applied the point collocation numerical technique to analyze the acoustic attenuation performance of dissipative silencers of arbitrary cross section in the presence of flow. ${ }^{13}$ Albelda et al. presents a modal approach to evaluate the transversal modes and wavenumbers for dissipative mufflers with mean flow. The approach avoids iterative schemes associated with the nonlinear characteristic equation. ${ }^{14}$ Kirby compared the analytic and numerical mode matching methods for modeling automotive dissipative silencers with mean flow, and the results demonstrated that both approaches deliver fast and accurate predictions. ${ }^{15}$ Elnady et al. proposed a new segmentation approach based on two-port analysis techniques for the modeling of automotive mufflers with two flow ducts coupled through a perforate. The two-port simulation results show good agreement with the measurements and the simulations using the classical four-port elements. ${ }^{16}$ Recently, Lato and Mohany presented 
an experimental investigation of the attenuation mechanism of a Herschel-Quincke device and its effectiveness in damping pressure pulsations when applied to a resonant piping system. ${ }^{17}$

With the implementation of increasingly strict emission regulations, small-displacement vehicles become more and more popular. The two-pass perforated hybrid mufflers are widely used in the exhaust system of small-displacement automobiles, however, no computational or experimental works have been published in the public literature to determine the acoustic attenuation characteristics of the hybrid mufflers. The 1-D analytical approach has no preference regarding a PC's performance, may capture the acoustic response of mufflers quickly, and becomes an effective tool for the acoustic analysis of mufflers especially in the stage of initial design of mufflers. The motivation of this paper is to develop a 1-D analytical approach to predict and analyze the acoustic attenuation performance of the two-pass perforated hybrid mufflers.

Following the introduction, the 1-D analytical approach is developed in Section 2. Section 3 presents appropriate acoustic impedance expressions for perforation in the presence of mean flow. In Section 4, the fitting expressions of the complex acoustic wave number and impedance of long fiber glass wool with filling density $151.4 \mathrm{~g} / \mathrm{L}$ are presented by the curve fitting based on the averaged values of measurements. Transmission loss of the hybrid mufflers is measured to validate the 1-D approach as well as fitting formulas of complex impedance and wavenumber of the sound-absorbing material in Section 5. Then the 1-D approach is employed to examine the effects of geometric parameters and mean flow on the acoustic attenuation performance of the hybrid mufflers in Section 6. Finally, this work concludes with some final remarks.

\section{THEORY}

The two-pass perforated hybrid muffler is shown in Fig. 1. The muffler is divided into three chambers by perforated bulkheads. The right chamber is filled with sound-absorbing material, the inlet tube with perforated section in the left chamber inserts into the middle chamber, and the outlet perforated tube inserts into the left chamber. Flow velocity in the local region of the left and middle chambers is high relatively; however, it is difficult for the 1-D analytical approach to consider the convection effects of complex non-uniform flow in chambers on acoustic propagation. Hence, the convective effect in inlet and outlet tubes is only taken into account. The dissipative effect of mean flow in perforated sections is only considered by selecting appropriate acoustic impedance for perforation.

Following the works of Peat, ${ }^{1}$ the sound pressures and particle velocities at the two ends of the perforated section, for example the ends $\left(x_{2}=0\right.$ and $\left.x_{2}=l_{p}\right)$ of the perforated section in the left chamber, are related as:

$$
\left\{\begin{array}{c}
p_{t}(0) \\
\rho_{0} c_{0} u_{t}(0) \\
p_{e}(0) \\
\rho_{0} c_{0} u_{e}(0)
\end{array}\right\}=\left[R_{0}\right]\left\{\begin{array}{c}
p_{t}\left(l_{p}\right) \\
\rho_{0} c_{0} u_{t}\left(l_{p}\right) \\
p_{e}\left(l_{p}\right) \\
\rho_{0} c_{0} u_{e}\left(l_{p}\right)
\end{array}\right\} ;
$$

where $p$ is the sound pressure, $u$ is the particle velocity, $\rho_{0}$ is the density of air, $c_{0}$ is the speed of sound in air, the mean flow Mach number in perforated tube and acoustic impedance of the

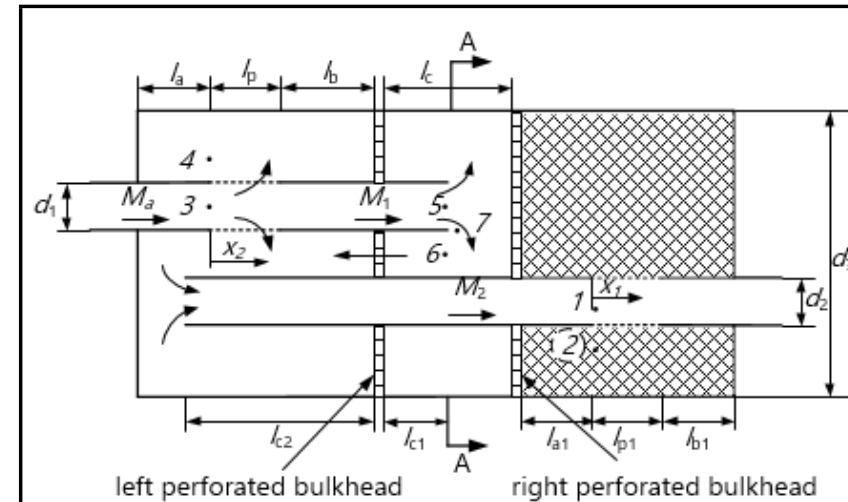

(a) For the case of $l_{c 2} \geq l_{p}+l_{b}$

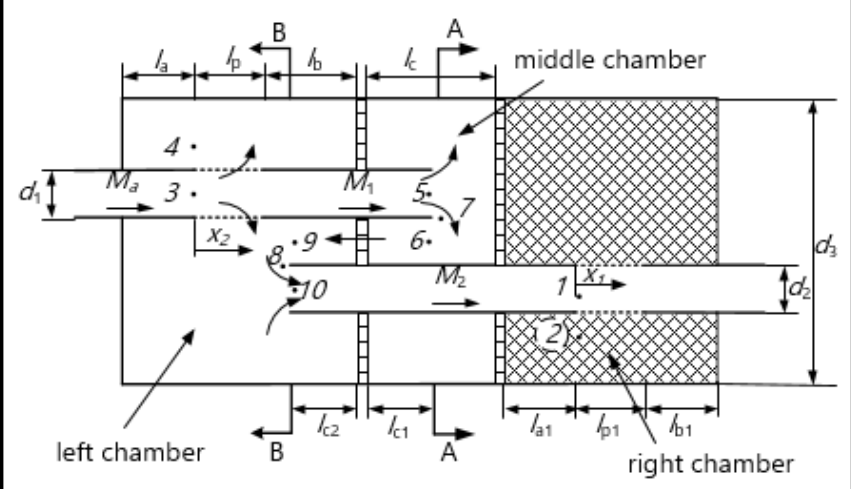

(b) For the case of $l_{c 2}<l_{p}+l_{b}$

Figure 1. Two-pass perforated tube hybrid muffler.

perforated tube are included in matrix $\left[R_{0}\right]$, and the subscripts $t$ and $e$ represent the perforated tube and empty chamber, respectively.

Ignoring the air flow in the right chamber, the soundabsorbing material is treated as an equivalent fluid with complex-valued density and sound speed. According to Eq. (1), the sound pressures and particle velocities at the two ends of perforated tube in right chamber may be expressed as:

$$
\left\{\begin{array}{c}
p_{1}(0) \\
\rho_{0} c_{0} u_{1}(0) \\
p_{2}(0) \\
\rho_{c} c_{c} u_{2}(0)
\end{array}\right\}=\left[\begin{array}{l}
{\left[A_{11}\right]\left[A_{12}\right]} \\
{\left[A_{21}\right]\left[A_{22}\right]}
\end{array}\right]\left\{\begin{array}{c}
p_{1}\left(l_{p 1}\right) \\
\rho_{0} c_{0} u_{1}\left(l_{p 1}\right) \\
p_{2}\left(l_{p 1}\right) \\
\rho_{c} c_{c} u_{2}\left(l_{p 1}\right)
\end{array}\right\} ;
$$

where $\rho_{c}$ is the complex density of sound-absorbing material, $c_{c}$ is the complex speed of sound in sound-absorbing material, $\left[A_{i j}\right](i=1,2, j=1,2)$ are the $2 \times 2$ matrices, and the subscript 1 and 2 represent the outlet perforated tube and the right chamber, respectively.

The rigid wall in the right chamber yields:

$$
\rho_{c} c_{c} u_{2}\left(l_{p 1}\right) / p_{2}\left(l_{p 1}\right)=\mathrm{j} \tan \left(k_{c} l_{b 1}\right)
$$

where $\mathrm{j}=\sqrt{-1}$ is the imaginary unit, $k_{c}$ is complex wavenumber of sound-absorbing material. The overall transfer matrices of the two muffler configurations are derived as below.

\subsection{For the Case of $l_{c 2} \geq l_{p}+l_{b}$}

The two-pass perforated hybrid muffler with $l_{c 2} \geq l_{p}+l_{b}$ is shown in Fig. 1(a), the sound pressures and particle velocities at the two ends of the perforated section in left chamber are 
related as:

$$
\left\{\begin{array}{c}
p_{3}(0) \\
\rho_{0} c_{0} u_{3}(0) \\
p_{4}(0) \\
\rho_{0} c_{0} u_{4}(0)
\end{array}\right\}=\left[\begin{array}{l}
{\left[B_{11}\right]\left[B_{12}\right]} \\
{\left[B_{21}\right]\left[B_{22}\right]}
\end{array}\right]\left\{\begin{array}{c}
p_{3}\left(l_{p}\right) \\
\rho_{0} c_{0} u_{3}\left(l_{p}\right) \\
p_{4}\left(l_{p}\right) \\
\rho_{0} c_{0} u_{4}\left(l_{p}\right)
\end{array}\right\} ;
$$

where $\left[B_{i j}\right](i=1,2, j=1,2)$ are the $2 \times 2$ matrices, and the subscripts 3 and 4 represent the inlet perforated tube and the left chamber, respectively.

By the transfer matrix method, the following expressions may be obtained:

$$
\begin{aligned}
& \left\{\begin{array}{c}
p_{3}\left(l_{p}\right) \\
\rho_{0} c_{0} u_{3}\left(l_{p}\right)
\end{array}\right\}= \\
& e^{-\mathrm{j} M_{1} k_{1} l_{1}}\left[\begin{array}{cc}
\cos \left(k_{1} l_{1}\right) & \mathrm{j} \sin \left(k_{1} l_{1}\right) \\
\mathrm{j} \sin \left(k_{1} l_{1}\right) & \cos \left(k_{1} l_{1}\right)
\end{array}\right]\left\{\begin{array}{c}
p_{5} \\
\rho_{0} c_{0} u_{5}
\end{array}\right\}= \\
& {[C]\left\{\begin{array}{c}
p_{5} \\
\rho_{0} c_{0} u_{5}
\end{array}\right\} \text {; }} \\
& \left\{\begin{array}{c}
p_{7} \\
\rho_{0} c_{0} u_{7}
\end{array}\right\}=\left[\begin{array}{cc}
\cos \left(k_{0} l_{2}\right) & \mathrm{j} \sin \left(k_{0} l_{2}\right) \\
\mathrm{j} \sin \left(k_{0} l_{2}\right) & \cos \left(k_{0} l_{2}\right)
\end{array}\right]\left[\begin{array}{cc}
1 & \zeta_{r} / z_{n} \\
0 & 1 / z_{n}
\end{array}\right] \times \\
& {\left[\begin{array}{cc}
\cos \left(k_{c} l_{3}\right) & \mathrm{j} \sin \left(k_{c} l_{3}\right) \\
\mathrm{j} \sin \left(k_{c} l_{3}\right) & \cos \left(k_{c} l_{3}\right)
\end{array}\right]\left\{\begin{array}{c}
p_{2}(0) \\
\rho_{c} c_{c} u_{2}(0)
\end{array}\right\}=} \\
& {[D]\left\{\begin{array}{c}
p_{2}(0) \\
\rho_{c} c_{c} u_{2}(0)
\end{array}\right\} \text {; }} \\
& \left\{\begin{array}{c}
p_{4}(0) \\
-\rho_{0} c_{0} u_{4}(0)
\end{array}\right\}= \\
& {\left[\begin{array}{cc}
\cos \left(k_{0} l_{4}\right) & \mathrm{j} \sin \left(k_{0} l_{4}\right) \\
\mathrm{j} \sin \left(k_{0} l_{4}\right) & \cos \left(k_{0} l_{4}\right)
\end{array}\right]\left[\begin{array}{cc}
1 & 0 \\
\frac{\mathrm{j} \tan \left(k_{0} l_{5}\right)\left(S_{3}-S_{1}-S_{2}\right)}{S_{3}-S_{1}} & \frac{S_{2}}{S_{3}-S_{1}}
\end{array}\right] \times} \\
& e^{-\mathrm{j} M_{2} k_{2} l_{6}}\left[\begin{array}{cc}
\cos \left(k_{2} l_{6}\right) & \mathrm{j} \sin \left(k_{2} l_{6}\right) \\
\mathrm{j} \sin \left(k_{2} l_{6}\right) & \cos \left(k_{2} l_{6}\right)
\end{array}\right]\left\{\begin{array}{c}
p_{1}(0) \\
\rho_{0} c_{0} u_{1}(0)
\end{array}\right\} ; \\
& \left\{\begin{array}{c}
p_{6} \\
\rho_{0} c_{0} u_{6}
\end{array}\right\}=\left[\begin{array}{cc}
\cos \left(k_{0} l_{7}\right) & \mathrm{j} \sin \left(k_{0} l_{7}\right) \\
\mathrm{j} \sin \left(k_{0} l_{7}\right) & \cos \left(k_{0} l_{7}\right)
\end{array}\right]\left[\begin{array}{cc}
1 & \zeta_{l} \\
0 & 1
\end{array}\right] \times \\
& {\left[\begin{array}{cc}
\cos \left(k_{0} l_{8}\right) & \mathrm{j} \sin \left(k_{0} l_{8}\right) \\
\mathrm{j} \sin \left(k_{0} l_{8}\right) & \cos \left(k_{0} l_{8}\right)
\end{array}\right]\left\{\begin{array}{c}
p_{4}\left(l_{p}\right) \\
-\rho_{0} c_{0} u_{4}\left(l_{p}\right)
\end{array}\right\} ;}
\end{aligned}
$$

where $k_{0}$ is the wave number, $k_{1}=k_{0} /\left(1-M_{1}^{2}\right), k_{2}=$ $k_{0} /\left(1-M_{2}^{2}\right), l_{1}=l_{b}+t_{b l}+l_{c 1}+\delta_{c 1}, l_{2}=l_{c}-l_{c 1}-\delta_{c 1}$, $l_{3}=l_{a 1}, l_{4}=l_{c 2}+\delta_{c 2}-l_{p}-l_{b}, l_{5}=l_{a}+l_{p}+l_{b}-l_{c 2}-\delta_{c 2}$, $l_{6}=l_{c 2}+\delta_{c 2}+t_{b l}+l_{c}+t_{b r}+l_{a 1}, l_{7}=l_{c 1}+\delta_{c 1}, l_{8}=l_{b}, \delta_{c 1}$ and $\delta_{c 2}$ are the end corrections of extensions for the inlet tube into the middle chamber and outlet tube into the left chamber, respectively, which may be calculated using expression (17) in the paper of Kang and $\mathrm{Ji}^{18} t_{b l}$ and $t_{b r}$ are the thickness of the left and right bulkheads, $\zeta_{l}$ and $\zeta_{r}$ are specific acoustic impedance ratio of perforations on the left and right bulkheads, respectively. $z_{n}$ is the acoustic impedance ratio of sound absorbing material to air, $S_{1}, S_{2}$ and $S_{3}$ are the cross-sectional areas of inlet and outlet tubes as well as chamber, respectively.

Expressions in Eqs. (7)-(8) may be rewritten as:

$$
\begin{aligned}
& \left\{\begin{array}{c}
p_{4}(0) \\
\rho_{0} c_{0} u_{4}(0)
\end{array}\right\}=[E]\left\{\begin{array}{c}
p_{1}(0) \\
\rho_{0} c_{0} u_{1}(0)
\end{array}\right\} ; \\
& \left\{\begin{array}{c}
p_{4}\left(l_{p}\right) \\
\rho_{0} c_{0} u_{4}\left(l_{p}\right)
\end{array}\right\}=[F]\left\{\begin{array}{c}
p_{6} \\
\rho_{0} c_{0} u_{6}
\end{array}\right\} .
\end{aligned}
$$

Substituting Eqs. (6) and (9) in Eq. (2) gets:

$$
\begin{gathered}
\left\{\begin{array}{c}
p_{4}(0) \\
\rho_{0} c_{0} u_{4}(0) \\
p_{7} \\
\rho_{0} c_{0} u_{7}
\end{array}\right\}= \\
{\left[\begin{array}{c}
\left.[E]\left[A_{11}\right][E]\left[A_{12}\right]\right] \\
{[D]\left[A_{21}\right][D]\left[A_{22}\right]}
\end{array}\right]\left\{\begin{array}{c}
p_{1}\left(l_{p 1}\right) \\
\rho_{0} c_{0} u_{1}\left(l_{p 1}\right) \\
p_{2}\left(l_{p 1}\right) \\
\rho_{c} c_{c} u_{2}\left(l_{p 1}\right)
\end{array}\right\}=} \\
{[G]\left\{\begin{array}{c}
p_{1}\left(l_{p 1}\right) \\
\rho_{0} c_{0} u_{1}\left(l_{p 1}\right) \\
p_{2}\left(l_{p 1}\right) \\
\rho_{c} c_{c} u_{2}\left(l_{p 1}\right)
\end{array}\right\} .}
\end{gathered}
$$

Substituting Eqs. (5) and (10) in Eq. (4) yields:

$$
\begin{aligned}
\left\{\begin{array}{c}
p_{3}(0) \\
\rho_{0} c_{0} u_{3}(0) \\
p_{4}(0) \\
\rho_{0} c_{0} u_{4}(0)
\end{array}\right\}= & {\left.\left[\begin{array}{c}
{\left[B_{11}\right][C]\left[B_{12}\right][F]} \\
{\left[B_{21}\right][C]\left[B_{22}\right][F]}
\end{array}\right\} \begin{array}{c}
p_{5} \\
\rho_{0} c_{0} u_{5} \\
p_{6} \\
\rho_{0} c_{0} u_{6}
\end{array}\right\}=} \\
& {[H]\left\{\begin{array}{c}
p_{5} \\
\rho_{0} c_{0} u_{5} \\
p_{6} \\
\rho_{0} c_{0} u_{6}
\end{array}\right\} . }
\end{aligned}
$$

On the cross-section A-A in Fig. 1(a), the continuity conditions of sound pressure and acoustic mass velocity at the intersection give:

$$
\begin{aligned}
& p_{5}=p_{6}=p_{7} ; \\
& \rho 0 c_{0} u_{5} S_{5}=\rho 0 c_{0} u_{6} S_{6}+\rho 0 c_{0} u_{7} S_{7} ;
\end{aligned}
$$

where $S_{5}=S_{1}, S_{6}=S_{3}-S_{1}-S_{2}$ and $S_{7}=S_{3}-S_{2}$.

Substituting Eq. (13) in Eq. (12) obtains:

$$
\left\{\begin{array}{c}
p_{3}(0) \\
\rho_{0} c_{0} u_{3}(0) \\
p_{4}(0) \\
\rho_{0} c_{0} u_{4}(0)
\end{array}\right\}=[I]\left\{\begin{array}{c}
\rho_{0} c_{0} u_{6} \\
p_{7} \\
\rho_{0} c_{0} u_{7}
\end{array}\right\}=\left[\begin{array}{l}
{\left[I_{1}\right]} \\
{\left[I_{2}\right]}
\end{array}\right]\left\{\begin{array}{c}
\rho_{0} c_{0} u_{6} \\
p_{7} \\
\rho_{0} c_{0} u_{7}
\end{array}\right\} ;
$$

where $I_{m 1}=H_{m 2} S_{6} / S_{5}+H_{m 4}, I_{m 2}=H_{m 1}+H_{m 3}, I_{m 3}=$ $H_{m 2} S_{7} / S_{5}, m=1 \sim 4$.

Substituting Eq. (3) in Eq. (11) gets:

$$
\left\{\begin{array}{c}
p_{4}(0) \\
\rho_{0} c_{0} u_{4}(0) \\
p_{7} \\
\rho_{0} c_{0} u_{7}
\end{array}\right\}=[J]\left\{\begin{array}{c}
p_{1}\left(l_{p 1}\right) \\
\rho_{0} c_{0} u_{1}\left(l_{p 1}\right) \\
\rho_{c} c_{c} u_{2}\left(l_{p 1}\right)
\end{array}\right\} ;
$$

where $J_{m n}=G_{m n}(m=1 \sim 4, n=1 \sim 2), J_{m 3}=$ $G_{m 3}+\mathrm{j} \tan \left(k_{c} l_{b l}\right) G_{m 4}(m=1 \sim 4)$.

Equations (14) and (15) both contain the terms $p_{4}(0)$ and $\rho_{0} c_{0} u_{4}(0)$, may be rewritten as:

$$
\begin{aligned}
& \left\{\begin{array}{c}
\rho_{0} c_{0} u_{6} \\
p_{7} \\
\rho_{0} c_{0} u_{7}
\end{array}\right\}= \\
& \quad\left[\begin{array}{cc}
a_{1}-b_{1} a_{3} / b_{3} & a_{2}-b_{2} a_{3} / b_{3} \\
J_{31}-b_{1} J_{33} / b_{3} & J_{32}-b_{2} J_{33} / b_{3} \\
J_{41}-b_{1} J_{43} / b_{3} & J_{41}-b_{2} J_{43} / b_{3}
\end{array}\right]\left\{\begin{array}{c}
p_{1}\left(l_{p 1}\right) \\
\rho_{0} c_{0} u_{1}\left(l_{p 1}\right)
\end{array}\right\}= \\
& {[K]\left\{\begin{array}{c}
p_{1}\left(l_{p 1}\right) \\
\rho_{0} c_{0} u_{1}\left(l_{p 1}\right)
\end{array}\right\} ;}
\end{aligned}
$$

where $a_{n}=\left(J_{1 n}-I_{32} J_{3 n}-I_{33} J_{4 n}\right) / I_{31}, b_{n}=I_{41} a_{n}+$ $I_{42} J_{3 n}+I_{43} J_{4 n}-J_{2 n}, n=1 \sim 3$. 
Substituting Eq. (14) in Eq. (16) yields the whole transfer matrix of the muffler as:

$$
\begin{gathered}
\left\{\begin{array}{c}
p_{i} \\
\rho_{0} c_{0} u_{i}
\end{array}\right\}=e^{-\mathrm{j} M_{a} k_{a} l_{1}}\left[\begin{array}{cc}
\cos \left(k_{a} l_{a}\right) & \mathrm{j} \sin \left(k_{a} l_{a}\right) \\
\mathrm{j} \sin \left(k_{a} l_{a}\right) & \cos \left(k_{a} l_{a}\right)
\end{array}\right]\left[I_{1}\right][K] \times \\
e^{-\mathrm{j} M_{2} k_{2} l_{b 1}}\left[\begin{array}{cc}
\cos \left(k_{2} l_{b 1}\right) & \mathrm{j} \sin \left(k_{2} l_{b 1}\right) \\
\mathrm{j} \sin \left(k_{2} l_{b 1}\right) & \cos \left(k_{2} l_{b 1}\right)
\end{array}\right]\left\{\begin{array}{c}
p_{o} \\
\rho_{0} c_{0} u_{o}
\end{array}\right\}= \\
{[T]\left\{\begin{array}{c}
p_{o} \\
\rho_{0} c_{0} u_{o}
\end{array}\right\} ;}
\end{gathered}
$$

where $k_{a}=k_{0} /\left(1-M_{a}^{2}\right)$, the subscripts $i$ and $o$ represent the inlet and outlet of the muffler, respectively.

\subsection{For the Case of $l_{c 2}<l_{p}+l_{b}$}

The two-pass perforated hybrid muffler with $l_{c 2}<l_{p}+l_{b}$ is shown in Fig. 1(b), Eqs. (4)-(6) will be used in this section based on the foregoing analysis. The following expressions may be obtained by the transfer matrix method:

$$
\begin{aligned}
& \left\{\begin{array}{c}
p_{10} \\
\rho_{0} c_{0} u_{10}
\end{array}\right\}= \\
& e^{-\mathrm{j} M_{2} k_{2} l_{6}}\left[\begin{array}{cc}
\cos \left(k_{2} l_{1}\right) & \mathrm{j} \sin \left(k_{2} l_{1}\right) \\
\mathrm{j} \sin \left(k_{2} l_{1}\right) & \cos \left(k_{2} l_{1}\right)
\end{array}\right]\left\{\begin{array}{c}
p_{1}(0) \\
\rho_{0} c_{0} u_{1}(0)
\end{array}\right\}= \\
& {[E]\left\{\begin{array}{c}
p_{1}(0) \\
\rho_{0} c_{0} u_{1}(0)
\end{array}\right\} \text {; }} \\
& \left\{\begin{array}{c}
p_{4}\left(l_{p}\right) \\
\rho_{0} c_{0} u_{4}\left(l_{p}\right)
\end{array}\right\}=\left[\begin{array}{cc}
\cos \left(k_{0} l_{2}\right) & \mathrm{j} \sin \left(k_{0} l_{2}\right) \\
\mathrm{j} \sin \left(k_{0} l_{2}\right) & \cos \left(k_{0} l_{2}\right)
\end{array}\right]\left\{\begin{array}{c}
p_{8} \\
\rho_{0} c_{0} u_{8}
\end{array}\right\}= \\
& {[F]\left\{\begin{array}{c}
p_{8} \\
\rho_{0} c_{0} u_{8}
\end{array}\right\} ;} \\
& \left\{\begin{array}{c}
p_{6} \\
\rho_{0} c_{0} u_{6}
\end{array}\right\}=\left[\begin{array}{cc}
\cos \left(k_{0} l_{3}\right) & \mathrm{j} \sin \left(k_{0} l_{3}\right) \\
\mathrm{j} \sin \left(k_{0} l_{3}\right) & \cos \left(k_{0} l_{3}\right)
\end{array}\right]\left[\begin{array}{cc}
1 & \zeta_{l} \\
0 & 1
\end{array}\right] \times \\
& {\left[\begin{array}{cc}
\cos \left(k_{0} l_{4}\right) & \mathrm{j} \sin \left(k_{0} l_{4}\right) \\
\mathrm{j} \sin \left(k_{0} l_{4}\right) & \cos \left(k_{0} l_{4}\right)
\end{array}\right]\left\{\begin{array}{c}
p_{9} \\
-\rho_{0} c_{0} u_{9}
\end{array}\right\} ;}
\end{aligned}
$$

where $k_{2}=k_{0} /\left(1-M_{2}^{2}\right), l_{1}=l_{c 2}+\sigma_{c 2}+t_{b l}+l_{c}+t_{b r}+l_{a 1}$, $l_{2}=l_{b}-l_{c 2}-\sigma_{c 2}, l_{3}=l_{c 1}+\sigma_{c 1}, l_{4}=l_{c 2}+\sigma_{c 2}$.

Equation (20) may be rewritten as:

$$
\left\{\begin{array}{c}
p_{6} \\
\rho_{0} c_{0} u_{6}
\end{array}\right\}=[G]\left\{\begin{array}{c}
p_{9} \\
-\rho_{0} c_{0} u_{9}
\end{array}\right\} \text {. }
$$

Substituting Eqs. (6) and (18) in Eq. (2) gets:

$$
\begin{aligned}
\left\{\begin{array}{c}
p_{10} \\
\rho_{0} c_{0} u_{10} \\
p_{7} \\
\rho_{0} c_{0} u_{7}
\end{array}\right\}= & {\left[\begin{array}{c}
\left.[E]\left[A_{11}\right][E]\left[A_{12}\right]\right] \\
{[D]\left[A_{21}\right][D]\left[A_{22}\right]}
\end{array}\right]\left\{\begin{array}{c}
p_{1}\left(l_{p 1}\right) \\
\rho_{0} c_{0} u_{1}\left(l_{p 1}\right) \\
p_{2}\left(l_{p 1}\right) \\
\rho_{c} c_{c} u_{2}\left(l_{p 1}\right)
\end{array}\right\}=} \\
& {[H]\left\{\begin{array}{c}
p_{1}\left(l_{p 1}\right) \\
\rho_{0} c_{0} u_{1}\left(l_{p 1}\right) \\
p_{2}\left(l_{p 1}\right) \\
\rho_{c} c_{c} u_{2}\left(l_{p 1}\right)
\end{array}\right\} . }
\end{aligned}
$$

Substituting Eqs. (5) and (19) in Eq. (4) obtains:

$$
\begin{aligned}
\left\{\begin{array}{c}
p_{3}(0) \\
\rho_{0} c_{0} u_{3}(0) \\
p_{4}(0) \\
\rho_{0} c_{0} u_{4}(0)
\end{array}\right\}= & {\left.\left[\begin{array}{l}
\left.\left[B_{11}\right][C]\left[B_{12}\right][F]\right] \\
{\left[B_{21}\right][C]\left[B_{22}\right][F]}
\end{array}\right\} \begin{array}{c}
p_{5} \\
\rho_{0} c_{0} u_{5} \\
p_{8} \\
\rho_{0} c_{0} u_{8}
\end{array}\right\}=} \\
& {[I]\left\{\begin{array}{c}
p_{5} \\
\rho_{0} c_{0} u_{5} \\
p_{8} \\
\rho_{0} c_{0} u_{8}
\end{array}\right\} . }
\end{aligned}
$$

The continuity conditions of sound pressure and acoustic mass velocity at the intersections A and B shown in Fig. 1(b) may be expressed as Eq. (13) and the following equations:

$$
\begin{aligned}
& p_{8}=p_{9}=p_{10} \\
& \rho 0 c_{0} u_{8} S_{8}=\rho 0 c_{0} u_{9} S_{9}+\rho 0 c_{0} u_{10} S_{10}
\end{aligned}
$$

where $S_{8}=S_{3}-S_{1}, S_{9}=S_{3}-S_{1}-S_{2}$ and $S_{10}=S_{2}$.

Combining Eqs. (13), (21) and (24) yields:

$$
\begin{aligned}
& \left\{\begin{array}{c}
p_{5} \\
\rho_{0} c_{0} u_{5} \\
p_{8} \\
\rho_{0} c_{0} u_{8}
\end{array}\right\}= \\
& {\left[\begin{array}{cccc}
0 & 0 & 1 & 0 \\
\left(G_{21}-\frac{G_{22} G_{11}}{G_{12}}\right) \frac{S_{6}}{S_{5}} & 0 & \frac{G_{22} S_{6}}{G_{12} S_{5}} & \frac{S_{7}}{S_{5}} \\
1 & 0 & 0 & 0 \\
\frac{-G_{11} S_{9}}{G_{12} S_{8}} & \frac{S_{10}}{S_{8}} & \frac{S_{9}}{G_{12} S_{8}} & 0
\end{array}\right]\left\{\begin{array}{c}
p_{10} \\
\rho_{0} c_{0} u_{10} \\
p_{7} \\
\rho_{0} c_{0} u_{7}
\end{array}\right\}=} \\
& {[J]\left\{\begin{array}{c}
p_{10} \\
\rho_{0} c_{0} u_{10} \\
p_{7} \\
\rho_{0} c_{0} u_{7}
\end{array}\right\} \text {. }}
\end{aligned}
$$

Substituting Eqs. (22) and (25) in Eq. (23) gets:

$$
\begin{gathered}
\left\{\begin{array}{c}
p_{3}(0) \\
\rho_{0} c_{0} u_{3}(0) \\
p_{4}(0) \\
\rho_{0} c_{0} u_{4}(0)
\end{array}\right\}=[I][J][H]\left\{\begin{array}{c}
p_{1}\left(l_{p 1}\right) \\
\rho_{0} c_{0} u_{1}\left(l_{p 1}\right) \\
p_{2}\left(l_{p 1}\right) \\
\rho_{c} c_{c} u_{2}\left(l_{p 1}\right)
\end{array}\right\}= \\
{[K]\left\{\begin{array}{c}
p_{1}\left(l_{p 1}\right) \\
\rho_{0} c_{0} u_{1}\left(l_{p 1}\right) \\
p_{2}\left(l_{p 1}\right) \\
\rho_{c} c_{c} u_{2}\left(l_{p 1}\right)
\end{array}\right\} .}
\end{gathered}
$$

The rigid wall in the left chamber gives:

$$
\rho_{0} c_{0} u_{4}(0) / p_{4}(0)=\mathrm{j} \tan \left(k_{0} l_{a}\right)
$$

Substituting Eqs. (3) and (27) in Eq. (26) gets the transfer matrix between inlet and outlet of the hybrid muffler, which may be expressed as:

$$
\begin{gathered}
\left\{\begin{array}{c}
p_{i} \\
\rho_{0} c_{0} u_{i}
\end{array}\right\}=e^{-\mathrm{j} M_{a} k_{a} l_{1}}\left[\begin{array}{cc}
\cos \left(k_{a} l_{a}\right) & \mathrm{j} \sin \left(k_{a} l_{a}\right) \\
\mathrm{j} \sin \left(k_{a} l_{a}\right) & \cos \left(k_{a} l_{a}\right)
\end{array}\right]\left[I_{1}\right][L] \times \\
e^{-\mathrm{j} M_{2} k_{2} l_{b 1}}\left[\begin{array}{cc}
\cos \left(k_{2} l_{b 1}\right) & \mathrm{j} \sin \left(k_{2} l_{b 1}\right) \\
\mathrm{j} \sin \left(k_{2} l_{b 1}\right) & \cos \left(k_{2} l_{b 1}\right)
\end{array}\right]\left\{\begin{array}{c}
p_{o} \\
\rho_{0} c_{0} u_{o}
\end{array}\right\}= \\
{[T]\left\{\begin{array}{c}
p_{o} \\
\rho_{0} c_{0} u_{o}
\end{array}\right\}}
\end{gathered}
$$

where $L_{m n}=$

$K_{m n}-\frac{\left[K_{m 3}+\mathrm{j} K_{m 4} \tan \left(k_{c} l_{b l}\right)\right]\left[K_{4 n}+\mathrm{j} K_{3 n} \tan \left(k_{0} l_{a}\right)\right]}{K_{43}+\mathrm{j} K_{44} \tan \left(k_{c} l_{b l}\right)+\mathrm{j} \tan \left(k_{0} l_{a}\right)\left[K_{33}+\mathrm{j} K_{34} \tan \left(k_{c} l_{b l}\right)\right]}$ $(m, n=1 \sim 2)$.

The transmission loss of the hybrid muffler may be determined by substituting the elements of matrix $[T]$ of Eq. (17) or Eq. (28) in the following expression:

$T L=20 \log _{10}\left(\sqrt{\frac{S_{1}}{S_{2}}} \frac{\left(1+M_{1}\right)}{\left(1+M_{2}\right)} \frac{\left|T_{11}+T_{12}+T_{21}+T_{22}\right|}{2}\right) ;$

where $M_{1}$ and $M_{2}$ are the mean flow Mach number on the inlet and outlet of the muffler, respectively, and $T_{i j}(i=1 \sim 2$, $j=1 \sim 2$ ) are the elements of the matrix $[T]$. 


\section{ACOUSTIC PROPERTIES OF PERFORATION}

The acoustic characteristics of perforation are expressed by using the acoustic impedance. Chen presented the expressions for the specific acoustic impedance ratio of perforations with the grazing flow: ${ }^{19}$

$$
\begin{aligned}
& \zeta_{G}= \\
& \frac{\sqrt{8 \rho_{0} \mu \omega}\left(1+\frac{t_{w}}{d_{h}}\right)+\rho_{0} V_{G} r_{G}+\mathrm{j}\left[\rho_{0} \omega\left(t_{w}+\alpha d_{h}\right)+\rho_{0} V_{G} x_{G}\right]}{\rho_{0} c_{0} \phi} ; \\
& r_{G}=\left\{\begin{array}{lc}
0.1319 S_{t}^{3}-0.6638 S_{t}^{2}+1.313 & S_{t} \leq 2.96 ; \\
1.554 S_{t}-5.708 & 2.96<S_{t} \leq 4.20 ; \\
-0.6625 S_{t}+3.578 & 4.2<S_{t} \leq 5.90 ; \\
0.647 S_{t}-4.162 & 5.90<S_{t} \leq 6.43 ; \\
0 & S_{t}>6.43 ;
\end{array}\right. \\
& x_{G}=\left\{\begin{array}{lc}
0.1266 S_{t}^{3}-1.105 S_{t} & S_{t} \leq 2.7 ; \\
1.888 S_{t}-5.637 & 2.7<S_{t} \leq 3.51 ; \\
-1.05 S_{t}+4.662 & 3.51<S_{t} \leq 4.88 ; \\
0.4006 S_{t}-2.425 & 4.88<S_{t} \leq 6.05 ; \\
0 & S_{t}>6.05 ;
\end{array}\right.
\end{aligned}
$$$$
S_{t}=\omega d_{h} /\left(2 U_{c}\right) ; \quad U_{c}=0.048 V_{G} R e^{0.2} ; \quad R e=\rho_{0} V_{G} d_{h} / \mu ;
$$

where $\rho_{0}$ is density of air in orifices, $c_{0}$ is the speed of sound in air, $\mu$ is the dynamic viscosity of air, $\omega$ is the circular frequency, $t_{w}$ is the wall thickness of perforated tube, $d_{h}$ is the hole diameter, $\phi$ is the porosity of perforation, $V_{G}$ is the average velocity for the grazing flow, $r_{G}$ and $x_{G}$ are nondimensional acoustic resistance and reactance of an orifice contributed by grazing flow, respectively, $S_{t}$ is the Strouhal number and is related to $d_{h}$ for grazing flow, $U_{c}$ is the convection velocity of vorticity, Re is Reynolds number. $\alpha$ is the end correction coefficient expressed as: $:^{20}$

$$
\begin{gathered}
\alpha=0.85\left(1-1.4092 \phi^{0.5}+0.33818 \phi^{1.5}+0.06793 \phi^{2.5}-\right. \\
\left.0.02287 \phi^{3}+0.03015 \phi^{3.5}-0.01641 \phi^{4}\right)
\end{gathered}
$$

For the perforated facing, one side is air and another side is sound-absorbing material, for example the perforated section in right chamber shown in Fig. 1, the acoustic impedance of perforations is influenced by the acoustic property of porous material. Inspired by Ingard and Bolt as well as Kirby and Cummings, ${ }^{21,22}$ Eq. (30) is modified to consider the effect of sound-absorbing material acoustic properties on $\zeta_{G}$ and rewritten as:

$$
\begin{aligned}
& \zeta_{G}= \\
& \frac{\sqrt{8 \rho_{0} \mu \omega}\left(1+\frac{t_{w}}{d_{h}}\right)+\rho_{0} V_{G} r_{G}+\mathrm{j}\left[\rho_{0} \omega\left(t_{w}+\alpha^{\prime} d_{h}\right)+\rho_{0} V_{G} x_{G}\right]}{\rho_{0} c_{0} \phi}
\end{aligned}
$$

where $\alpha^{\prime}=0.5 \alpha\left(1+\rho_{n}\right)$ is the modified end correction coefficient for sound-absorbing material filling in one side of perforated sections, $\rho_{n}$ is complex density ratio of sound-absorbing material to air. Since $r_{G}$ and $x_{G}$ are contributed by the grazing flow, Eq. (32) is also applied to determine the specific acoustic impedance ratio for the right perforated bulkhead with $r_{G}=x_{G}=0$.

For the bias flow in perforated sections, like the left bulkhead, the specific acoustic impedance ratio of perforations may be expressed as: ${ }^{23}$

$$
\begin{aligned}
& \zeta_{B}=\frac{\rho_{0} V_{B}\left(r_{B}+\mathrm{j} x_{B}\right)}{\phi} ; \\
& r_{B}=a \times S_{t}^{4}+b \times S_{t}^{3}+c ; \quad x_{B}=d \times S_{t}+e ; \\
& a=\frac{116.6 R e^{-0.7617}}{(\phi+0.1946)\left(t_{w} / d_{h}+0.1658\right)} ; \\
& b=\frac{4.776 \times 10^{-5}\left(R e-1.544 \times 10^{4}\right)}{(\phi+0.2263)\left(t_{w} / d_{h}+0.2559\right)} ; \\
& c=-3.096 \phi+2.406 ; \\
& \left\{\begin{array}{l}
d=\frac{7.672 \times 10^{-3}}{\left(t_{w} / d_{h}\right)^{2.817}}+0.6704 \\
e=0
\end{array}\right. \\
& \left\{\begin{array}{l}
d=\frac{-2.869}{\phi^{0.244}}\left[\frac{1}{t_{w} / d_{h}}-7.402\right]\left(R e^{0.1}-2.08\right) \\
e=\left[\frac{7.672 \times 10^{-3}}{\left(t_{w} / d_{h}\right)^{2.817}}+0.6704\right] S_{t}^{\prime}-d \times S_{t}^{\prime}
\end{array}\right. \\
& S_{t}^{\prime}=4.940\left(t_{w} / d_{h}+8.997 \times 10^{-2}\right)\left(R e^{0.1}-1.854\right) ; \\
& S_{t}=\omega t_{w} / 2 V_{B} ; \quad R e=\rho V_{0} d_{h} / \mu ;
\end{aligned}
$$

where $V_{B}$ is average velocity of airflow through the hole, $r_{B}$ and $x_{B}$ is non-dimensional acoustic resistance and reactance of an orifice with bias flow, respectively. $S_{t}$ is the Strouhal number and related to $t_{w}$ for bias flow. $V_{0}$ is flow velocity of the medium with Mach number 0.05 in orifices, which is used to take into account effects of medium temperature on $\zeta_{B}$.

Considering the fact that the grazing flow and the bias flow occur simultaneously in the inlet perforated section. According to the works of Elnady, the acoustic impedance ratio of perforation $\zeta_{H}$ for hybrid flow is expressed as: ${ }^{16}$

$$
\begin{gathered}
\zeta_{H}=\operatorname{Re}\left[\frac{\mathrm{j} k_{0}}{\phi C_{d}}\left(\frac{t_{w}}{F\left(\mu^{\prime}\right)}+\frac{\delta_{r e} f_{\text {int }}}{F(\mu)}\right)\right]+\frac{1}{\phi}\left(1-\frac{2 J_{1}\left(k_{0} d_{h}\right)}{k_{0} d_{h}}\right)+ \\
\frac{0.3 M_{G}}{\phi}+\frac{1.15 M_{B}}{\phi C_{d}}+\mathrm{j} \operatorname{Im}\left[\frac{\mathrm{j} k_{0}}{\phi C_{d}}\left(\frac{t_{w}}{F\left(\mu^{\prime}\right)}+\frac{0.5 d_{h} f_{\text {int }}}{F(\mu)}\right)\right]
\end{gathered}
$$

where $C_{d}=1 / \sqrt{k_{1}+k_{2} / \lambda+k_{3} / \lambda^{2}}$ is called as the effective discharge coefficient, $k_{1}=2.1, k_{2}=-0.332$ and $k_{3}=-0.0566$ are for the bias-outflow as well as $k_{1}=1.72$, $k_{2}=0.138$ and $k_{3}=0.0127$ are for the bias-inflow, $\lambda$ is the ratio of the bias flow velocity to the grazing flow speed. ${ }^{24}$ $v=\mu / \rho_{0}$ is the kinematic viscosity, $\mu^{\prime}=2.179 \mu, M_{G}$ is the grazing flow Mach number, and $M_{B}$ is the bias flow Mach number inside holes. The rest of the parameters are defined as follows:

$$
\begin{aligned}
& K=\sqrt{-\frac{\mathrm{j} \omega}{v}} ; \quad K^{\prime}=\sqrt{-\frac{\mathrm{j} \omega}{v^{\prime}}} ; \\
& F\left(K d_{h}\right)=1-\frac{4 J_{1}\left(K d_{h} / 2\right)}{K d_{h} \cdot J_{0}\left(K d_{h} / 2\right)} ; \\
& \delta_{r e}=0.2 d_{h}+200 d_{h}^{2}+16000 d_{h}^{3} ; \\
& f_{\text {int }}=1-1.47 \sqrt{\phi}+0.47 \sqrt{\phi^{3}} ;
\end{aligned}
$$

$f_{\text {int }}$ is a correction factor for the orifice interaction effects. 


\section{ACOUSTIC PROPERTIES OF SOUND- ABSORBING MATERIAL}

Long fiber glass wool with a high thermal and corrosion resistance property is widely used in exhaust mufflers of vehicles, and adopted in the present works as sound-absorbing material. The two-load method is employed to measure the complex specific acoustic impedance and wavenumber of the material. It is necessary to separate each strand of long fiber glass wool into filaments by using the strong turbulent gas equipment. In the measurement, the material is fixed with a metal support with the perforation porosity greater than $80 \%$. The test sample should not be too thin, otherwise the inhomogeneity of filling may be amplified. And it should not be too thick, otherwise the high-frequency sound energy passing through the sample may be absorbed, which may affect the measurement accuracy. The intensity of the sound source should be large enough but should avoid the nonlinear effects and set as $120 \mathrm{~dB}$ in the present works. Since Lee has measured the acoustic property of the glass fiber with filling densities $100 \mathrm{~g} / \mathrm{L}$ and $200 \mathrm{~g} / \mathrm{L},{ }^{25}$ this study chose a medium filling density of $151.4 \mathrm{~g} / \mathrm{L}$, with an ambient temperature in measurements of $293 \mathrm{~K}$.

Fitting the data based on the average values of five measurements yields the formulas expressed as:

$$
\begin{aligned}
& k_{n}=k_{c} / k_{0}=1+66.67 f^{-0.7122}-\mathrm{j} 51.39 f^{-0.6582} ; \\
& z_{n}=z_{c} / z_{0}=1+11.75 f^{-0.4957}-\mathrm{j} 80.55 f^{-0.8191} ;
\end{aligned}
$$

where $f$ is frequency, $k_{n}$ and $z_{n}$ are complex wavenumber and impedance ratio of sound-absorbing material to air. Figure 2 illustrates that the fitting formulas match the measurements very well.

\section{TRANSMISSION LOSS MEASUREMENT WITH MEAN FLOW}

In order to validate the transfer matrices, the two-load method is employed to determine the transmission loss of the two-pass perforated hybrid mufflers in the presence of mean flow, and then the results are compared with predictions. The measurement set-up is shown in Fig. 3, which includes a blower system, a sound source box, impedance tubes, four probe microphones, two different acoustic loads, a power amplifier, a signal analyzer with multiple input-output channels and a computer. The computer pushes the specific sound source signal to the multi-channel signal analyzer, which transmits the signal to the sound source box through the power amplifier to drive loudspeakers. The PCB 377B26 probe microphones with diameter only $1.25 \mathrm{~mm}$ are mounted on the wall to detect the acoustic signal without disturbing the flow field and the sound field in the impedance tubes. The multi-channel signal analyzer then collects the acoustic signal of the four probe microphones and transmits them to the computer for spectrum analysis. The blower system provides an approximate steady fluid flux; two symmetrical coaxial loudspeakers are installed in the sound source box to generate sound. Moreover, the two acoustic loads should be different enough in the whole measurement frequency range to avoid blocking the airflow. The open end at the outlet is selected as one load, a hybrid muffler is selected as another load in this study. The spacing between

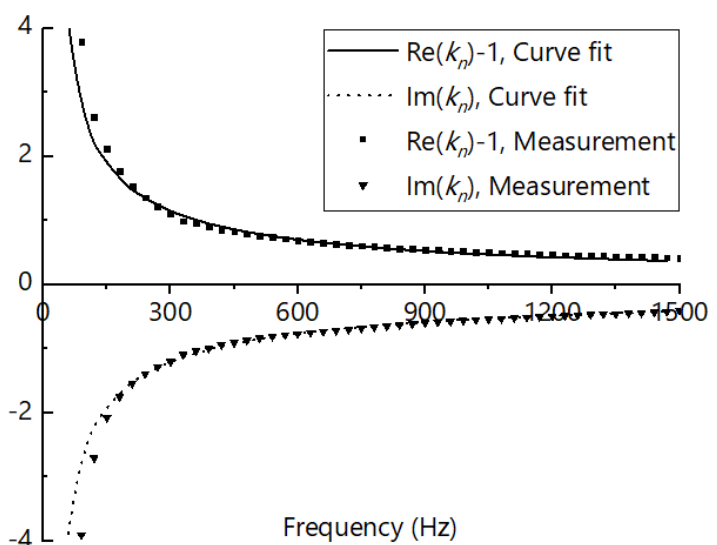

(a) The complex wavenumber ratio

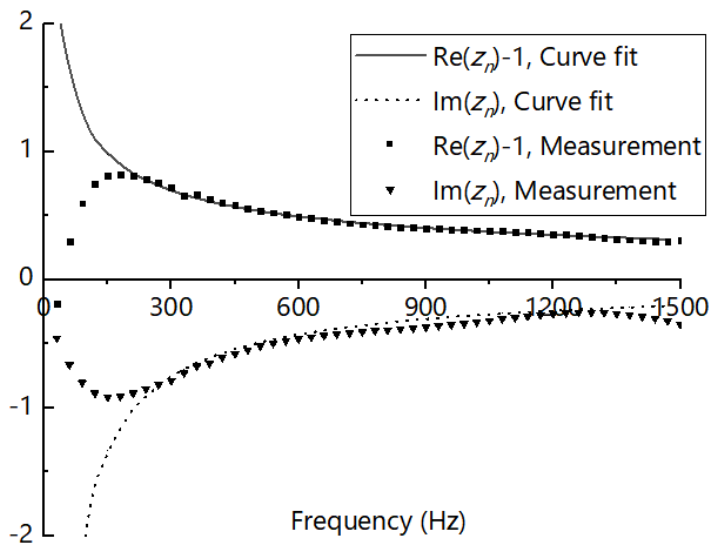

(b) The complex impedance ratio

Figure 2. Comparison of the results from measurements and fitting formulas.

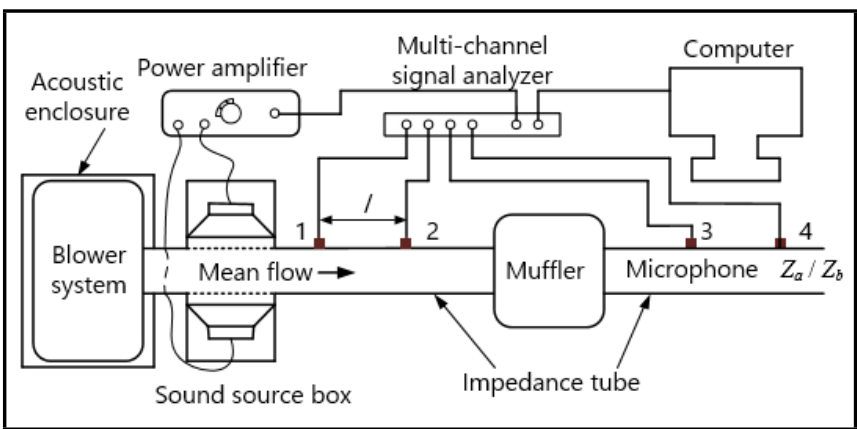

Figure 3. Set-up for transmission loss measurement in the presence of flow.

microphones $l$ is $0.045 \mathrm{~m}$, the lower and upper limit frequencies of the measurement set-up are about $75 \mathrm{~Hz}$ and $1900 \mathrm{~Hz}$, respectively, which satisfies the requirements of the measurements.

It is worthy to note the influence of background noise from the blower system and flow induced noise on measurements. A specially designed acoustic enclosure with intake and exhaust mufflers is used to attenuate the noise generated by the blower system. The flow regenerated noise inside the muffler possesses enough sound intensity to reduce the signal to noise ratio and affect the accuracy of experimental data. In addition, the noise being random in nature makes it difficult to apply random excitation which is usually used in the two-load method. In the present work, the fast sweep-sine signal and the ensemble averaging technique in the time domain are employed to 


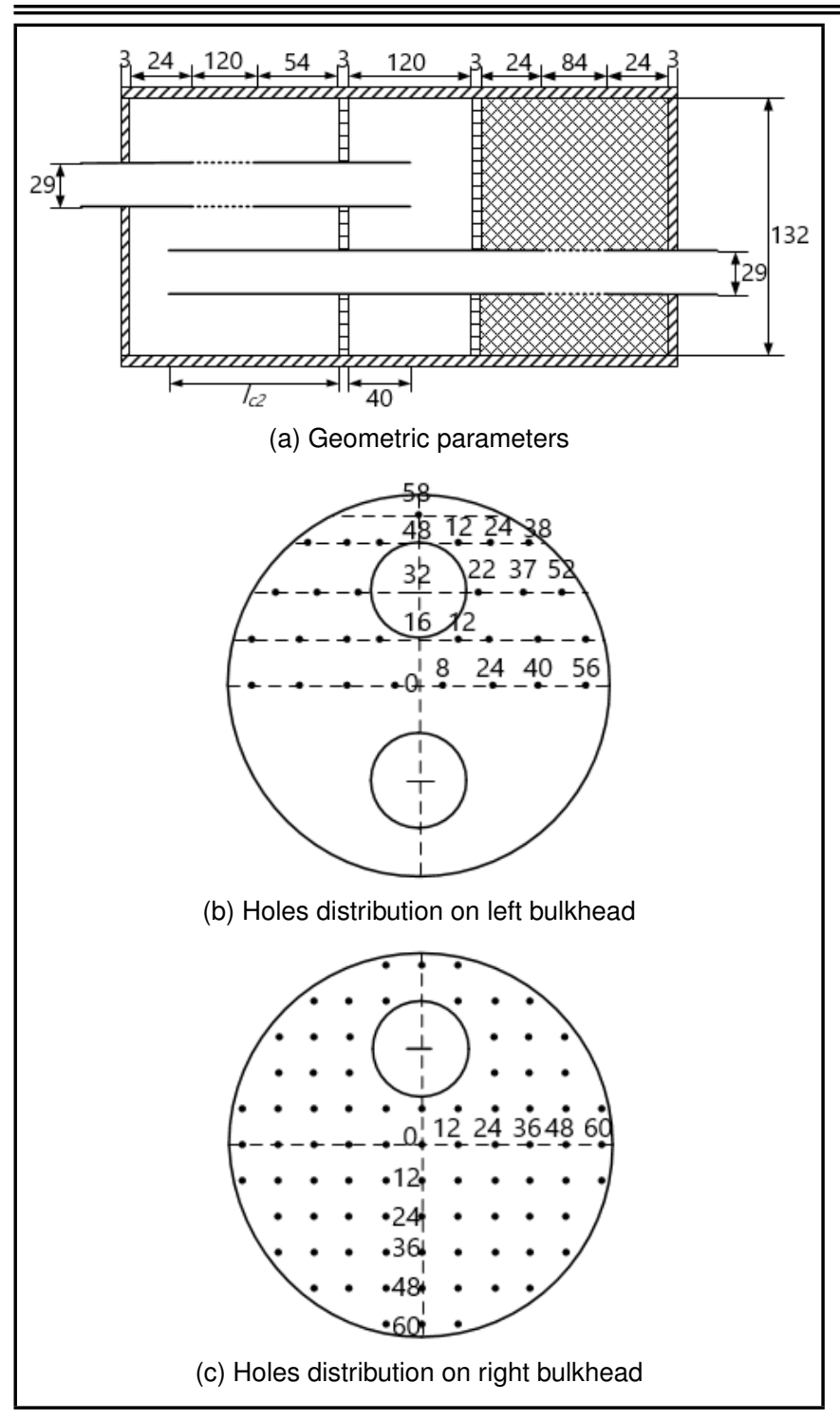

Figure 4. The geometric parameters of the two-pass perforated hybrid mufflers (unit: $\mathrm{mm}$ ).

enhance the signal to noise ratio. ${ }^{26}$ Finally, the transfer functions are exported for the transmission loss calculation. This measurement scheme may take more time and needs to process massive data in the time domain. For example, the sweep frequency band is $20 \mathrm{~Hz}$ to $2020 \mathrm{~Hz}$ with sweep rate 400 and repeats 300 times, the data volumes in time domain is up to $10 \mathrm{~GB}$.

The geometric parameters and holes distribution on the bulkheads of the two-pass perforated hybrid muffler are shown in Fig. 4, where $d_{1}=d_{2}=29 \mathrm{~mm}$ for the inner diameters of the inlet and outlet tubes with the wall thickness $t_{w}=1.5 \mathrm{~mm}$, $l_{c 2}=183 \mathrm{~mm}$ and $l_{c 2}=30 \mathrm{~mm}$ for the case of $l_{c 2} \geq l_{p}+l_{b}$ and $l_{c 2}<l_{p}+l_{b}$, respectively. The perforation parameters are: the perforated sections in left and right chambers with porosity $\phi_{\text {in }}=\phi_{\text {out }}=6.69 \%$ (eight holes per circle, ten circles in left chamber and seven circles in right chamber), the perforations on the left bulkhead with porosity $\phi_{l}=3.98 \%$ (21 holes on the upper and lower half planes, and 8 holes on the middle axis, in total 50 holes distributing as evenly as possible) and on the right bulkhead with porosity $\phi_{r}=6.125 \%$ (32 holes on the upper half plane, 39 holes on the lower half plane, and 11 holes on the middle axis, in total 82 holes), $d_{h}=3.5 \mathrm{~mm}$ for
Table 1. The flow field information (velocity unit: $\mathrm{m} / \mathrm{s}$ ).

\begin{tabular}{|c|c|c|c|c|c|c|c|}
\hline$l_{c 2}(\mathrm{~mm})$ & $M_{a}$ & $M_{1}$ & $M_{2}$ & $V_{\text {in } B}$ & $V_{\text {in } G}$ & $V_{\text {out }}$ & $V_{l}$ \\
\hline 183 & 0.05 & 0.028 & 0.05 & 6.4 & 9.5 & 17.1 & 13.0 \\
183 & 0.1 & 0.054 & 0.1 & 12.5 & 18.6 & 34.2 & 25.6 \\
30 & 0.05 & 0.028 & 0.05 & 6.4 & 9.5 & 17.1 & 13.0 \\
30 & 0.1 & 0.055 & 0.1 & 12.5 & 18.8 & 33.8 & 25.8 \\
\hline
\end{tabular}

all holes diameter.

The right chamber filled with sound-absorbing material is set as solid domain in CFD simulation due to ignoring the air flow. The walls contacting on the porous material of the outlet perforated tube and the right perforated bulkhead are treated as rigid walls. Therefore, the flow regime includes the inlet perforated tube, left and middle chambers, left perforated bulkhead and outlet tube. For a given Mach number on the inlet, the flow field information may be captured by CFD simulations, which are shown in Table 1 , where $M_{a}, M_{1}$ and $M_{2}$ are Mach numbers as denoted in Fig. 1, $V_{i n B}$ and $V_{i n G}$ are the average bias flow and grazing flow velocities in the inlet perforated section, respectively, $V_{\text {out }}$ is the average grazing flow velocity in the outlet perforated section, $V_{l}$ is the average bias flow velocity on the left perforated bulkhead.

Comparisons of transmission loss from the measurements and the 1-D analytical approach with a different Mach number of mean flow are shown in Figs. 5 and 6. For the case of $l_{c 2}=183 \mathrm{~mm}$, the predictions show reasonable agreements with experimental results up to $920 \mathrm{~Hz}, 880 \mathrm{~Hz}, 820 \mathrm{~Hz}$ for $M_{a}=0, M_{a}=0.05$ and $M_{a}=0.1$, respectively. For the case of $l_{c 2}=30 \mathrm{~mm}$, the predictions agree reasonably well with experimental data until $1100 \mathrm{~Hz}, 900 \mathrm{~Hz}$ and $850 \mathrm{~Hz}$ for $M_{a}=0, M_{a}=0.05$ and $M_{a}=0.1$, respectively. The deviation beyond these frequencies may be attributed to the effect of 3-D wave inside the muffler. The valid upper frequency for 1$\mathrm{D}$ analytical approach decreases as the Mach number of mean flow increases, the reason for this is that the plane wave cut-off frequency decreases with the increasing of the mean flow velocity. There are some spikes on the measurement curves for $M_{a}>0$, which may be attributed to the flow induced noise inside the mufflers.

\section{ANALYSIS}

Figure 7 illustrates the effect of the length $l_{c 2}$ on the transmission loss of the muffler in the absence of mean flow. It may be seen that the length $l_{c 2}$ mainly impacts the acoustic response of the muffler beyond $400 \mathrm{~Hz}$ and the resonance frequency, and transmission loss around the spike decreases with the increasing of the length $l_{c 2}$. The spike frequency shifts to lower frequency as the increase of the length $l_{c 2}$, which may be attributed to the combined effect of the perforated tube and extension length.

Figure 8 exhibits the impact of porosities of the right bulkhead on the acoustic attenuation characteristics of the muffler with $l_{c 2}=183 \mathrm{~mm}$ in absence of mean flow. It indicates that acoustic resonant effects are generated for the right bulkhead with low porosity. As $\phi_{r}$ increases, the transmission loss lowers at most frequencies and a flatter curve is observed.

The influence of the Mach number of mean flow on the acoustic attenuation properties of the hybrid muffler with $l_{c 2}=$ $183 \mathrm{~mm}$ is shown in Fig. 9. The results indicate that transmission loss of the muffler is increased at most frequencies due 


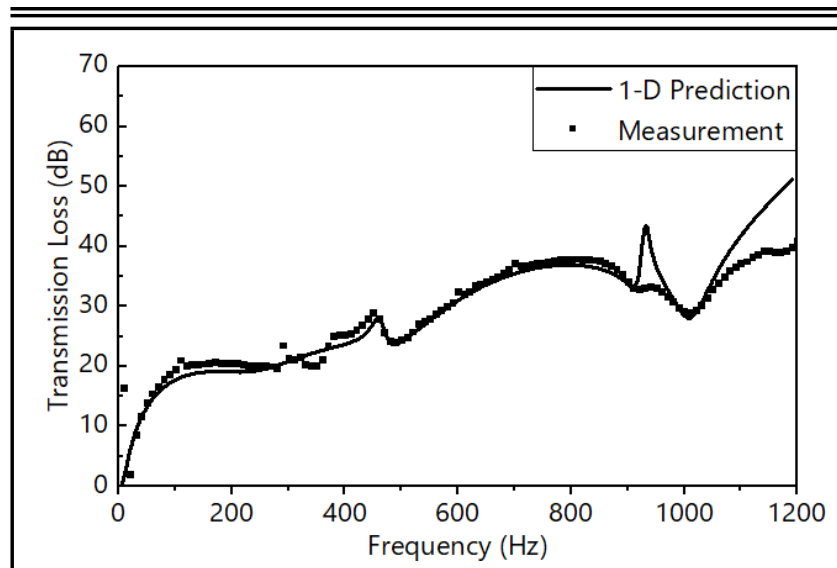

(a) For $M_{a}=0$

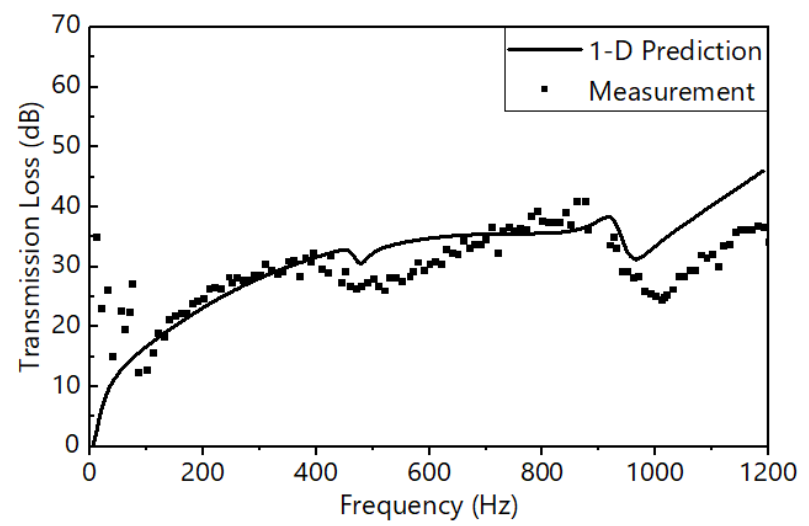

(b) For $M_{a}=0.05$

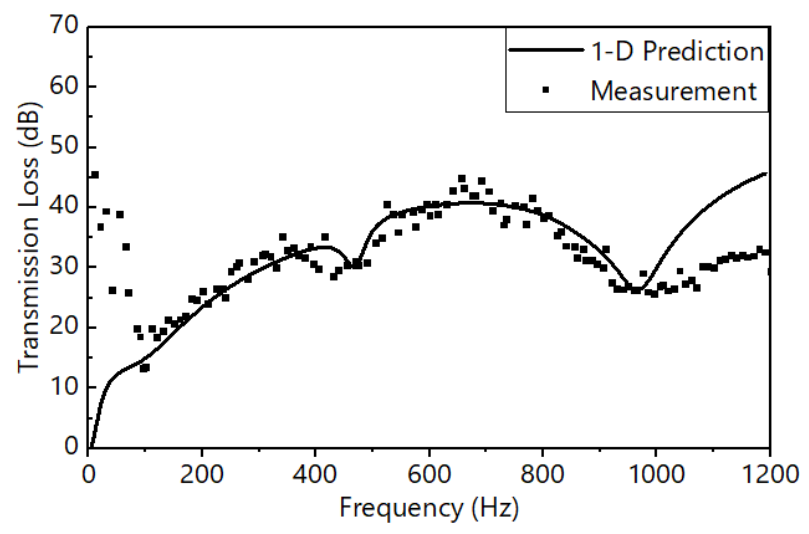

(c) For $M_{a}=0.1$

Figure 5. Comparison of transmission loss from measurements and predictions for the case of $l_{c 2}=183 \mathrm{~mm}$.

to the increased dissipative effects of perforations with an increase of mean flow velocity.

Figure 10 exhibits the effect of the porosities of the inlet perforated tube on the acoustic attenuation characteristics of the hybrid muffler with $M_{a}=0.1$. The flow field information for different porosities of the hybrid muffler is shown in Table 2, where $\nabla_{p}$ is the total pressure difference between the inlet and outlet. The results indicate that the transmission loss in the frequency range of $600 \mathrm{~Hz}$ to $800 \mathrm{~Hz}$ as well as the total pressure difference between the inlet and outlet increases as the decrease of the porosity of the inlet perforated tube. In Table 2, the bias velocities of the inlet perforated tube and the left perforated bulkhead decrease with the increase of the porosity, which reduces the acoustic attenuation performance of the hybrid muffler since dissipative effects in perforations with bias

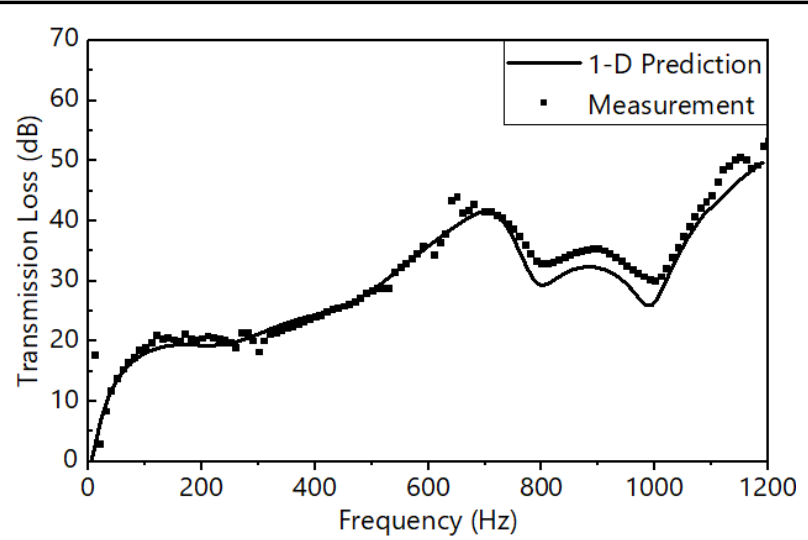

(a) For $M_{a}=0$

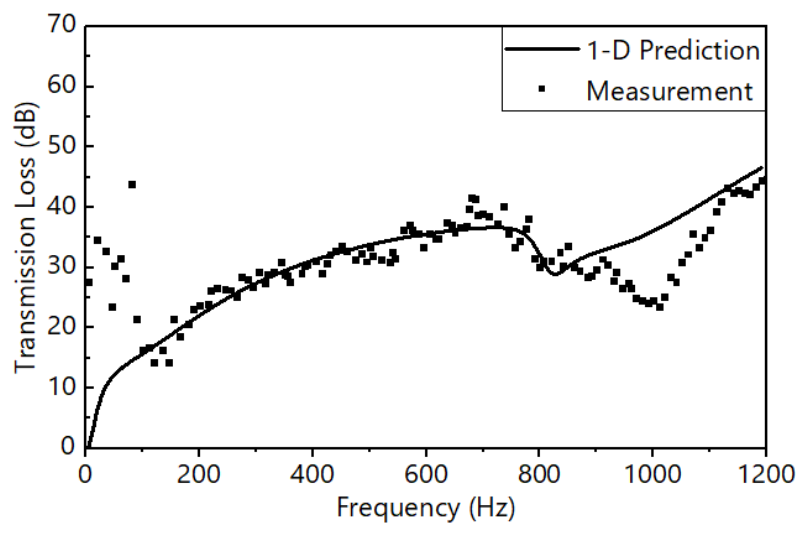

(b) For $M_{a}=0.05$

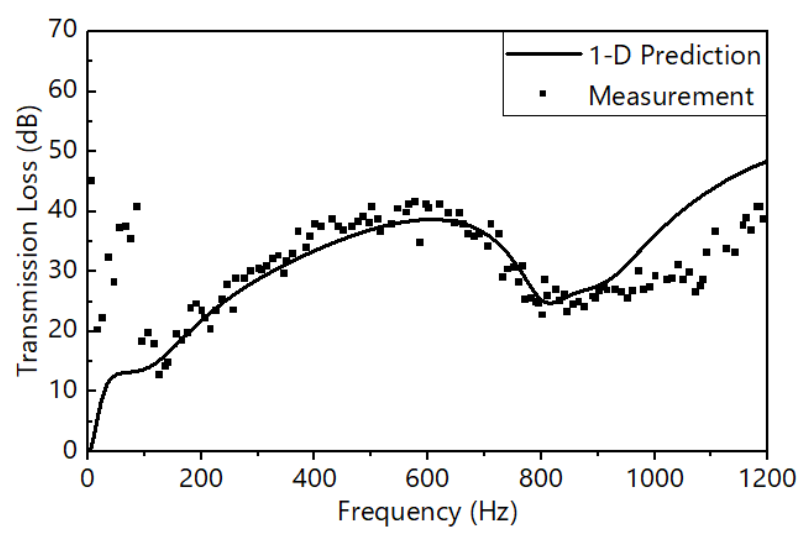

(c) For $M_{a}=0.1$

Figure 6. Comparison of transmission loss from measurements and predictions for the case of $l_{c 2}=30 \mathrm{~mm}$.

flow decrease as the decreasing of the bias flow velocity. Figure 11 shows the total pressure contour of the hybrid muffler with $\phi_{\text {in }}=6.69 \%$. The pressure drop mainly occurred in the left perforated section and on the left perforated bulkhead generated by the bias flow and flow reversing.

\section{CONCLUSIONS}

The 1-D analytical approach was presented to predict and analyze the acoustic attenuation performance of two-pass perforated hybrid mufflers with mean flow. When the convection effects in tubes and dissipative effects in perforated sections were considered, the transfer matrices of the hybrid mufflers were derived. The acoustic property of the long fiber glass wool with filling density $151.4 \mathrm{~g} / \mathrm{L}$ was measured by the two- 


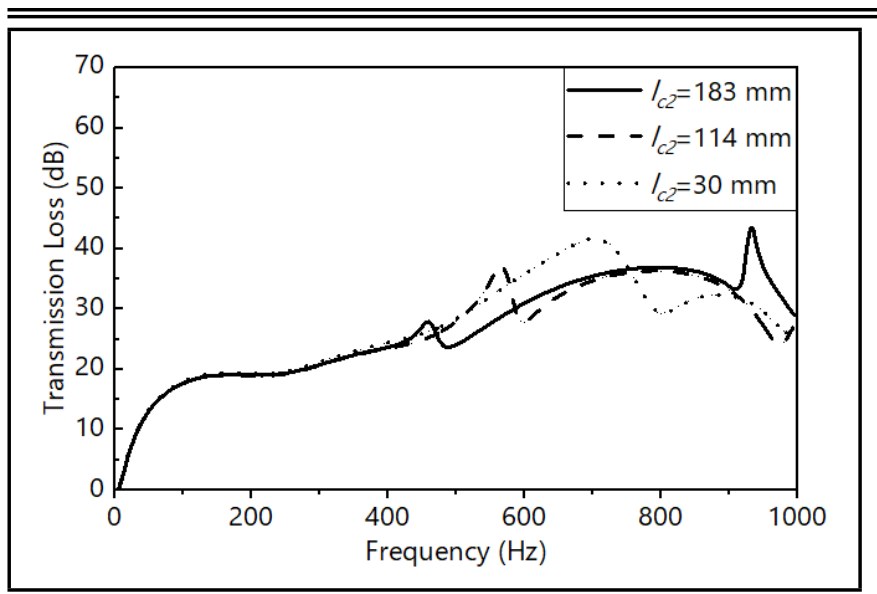

Figure 7. Effects of the length $l_{c 2}$ on the transmission loss of the muffler.

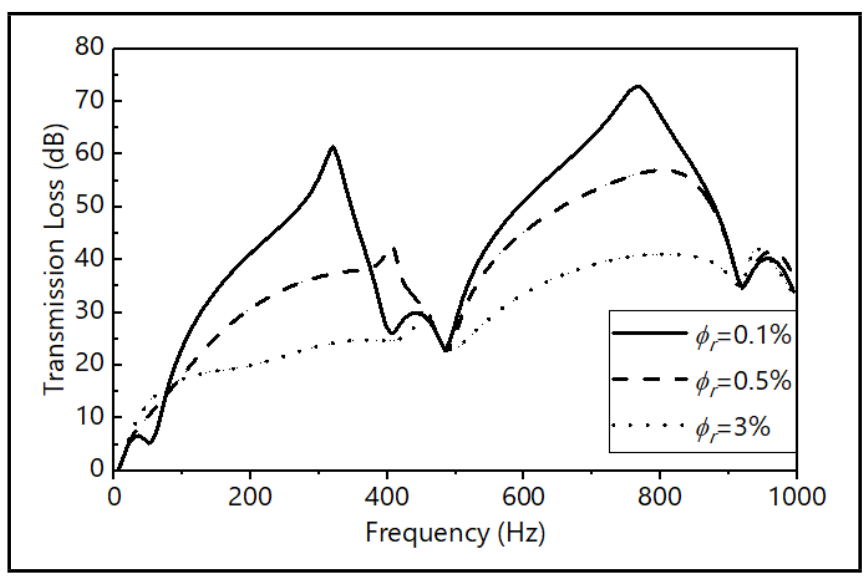

Figure 8. Influence of perforations on the right bulkhead on the acoustic response of the muffler.

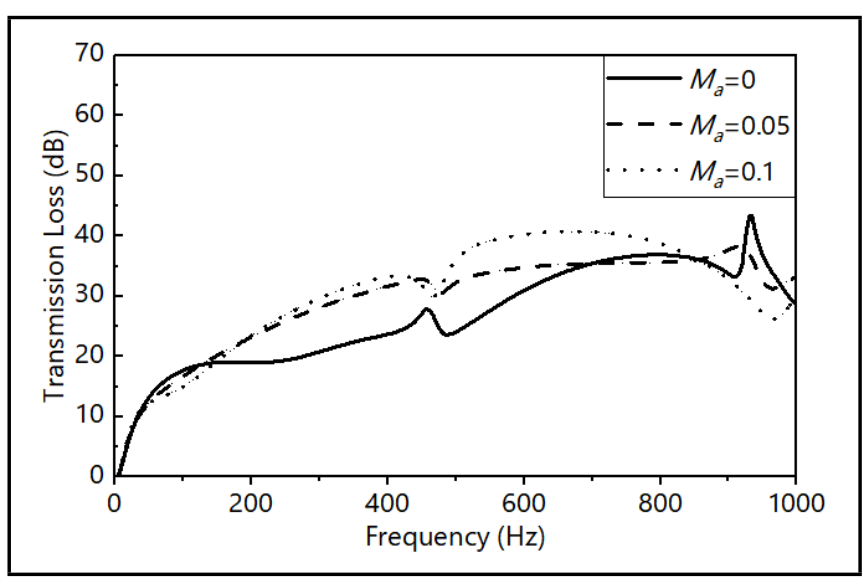

Figure 9. Influence of the Mach number on acoustic attenuation performance of the muffler.

load method, and then the expressions of complex wavenumber and impedance were obtained through curve fitting. The algorithms as well as empirical formulas were validated by comparing transmission loss from predictions and measurements. The results indicated that the 1-D solutions agreed reasonably well with measurements below the plane wave cut-off frequency and deviated at higher frequencies.

The 1-D approach was then applied to examine the effects of structural parameters and mean flow on the acoustic attenuation performance of the hybrid mufflers. Results showed that the length of the extended tube may affect the resonant fre-
Table 2. The flow field information for different porosities of the inlet perforated tube with $M_{a}=0.1$ (velocity unit: $\mathrm{m} / \mathrm{s}$ ).

\begin{tabular}{|c|c|c|c|c|c|c|c|}
\hline$\phi_{\text {in }}$ & $M_{1}$ & $M_{2}$ & $V_{\text {in B }}$ & $V_{\text {in }}$ & $V_{\text {out }}$ & $V_{l}$ & $\nabla p(\mathrm{~Pa})$ \\
\hline $4 \%$ & 0.062 & 0.1 & 17.0 & 21.3 & 34.2 & 29.3 & 1778 \\
$6.69 \%$ & 0.054 & 0.1 & 12.6 & 18.6 & 34.2 & 25.6 & 1628 \\
$10 \%$ & 0.050 & 0.1 & 9.2 & 17.2 & 34.2 & 23.6 & 1551 \\
\hline
\end{tabular}

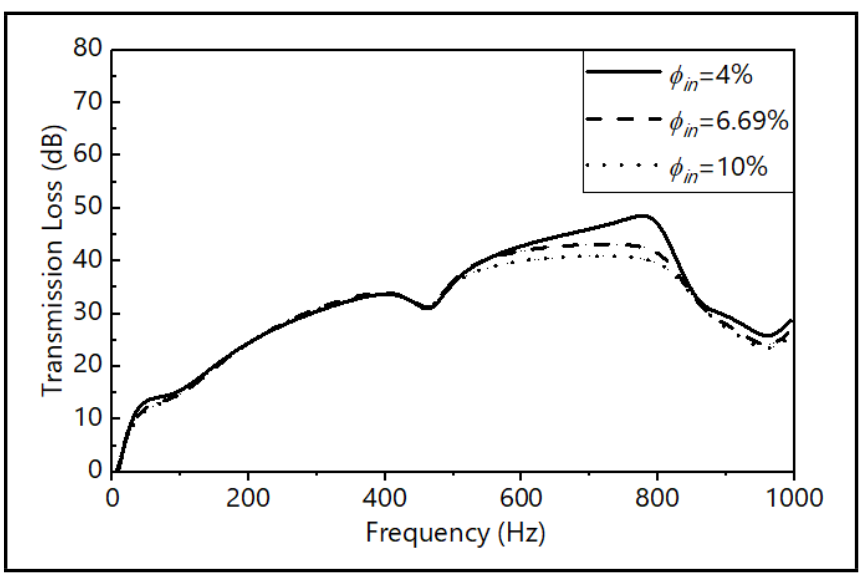

Figure 10. Influence of the porosities of the inlet perforated tube on acoustic response of the muffler with $M_{a}=0.1$.

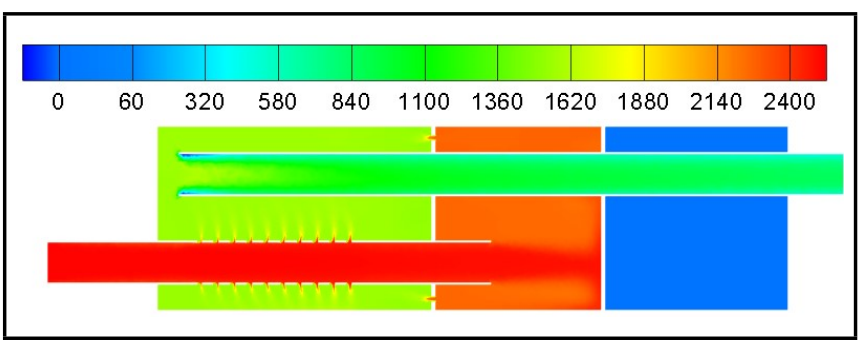

Figure 11. Total pressure contour for the hybrid muffler for $\phi_{i n}=6.69 \%$ with $M_{a}=0.1$.

quency which shifted to the lower frequency with increased length of the tube extension. Acoustic resonant effects were generated for the right bulkhead with low porosity, the transmission loss at most frequencies was decreased with the increased right perforated bulkhead porosity. The acoustic attenuation performance of the hybrid muffler at most frequencies increased with the increased mean flow Mach number. The decreased porosity of the inlet perforated tube increased the transmission loss of the muffler in the frequency range of $600 \mathrm{~Hz}$ to $800 \mathrm{~Hz}$ as well as the total pressure difference between the inlet and outlet.

\section{ACKNOWLEDGEMENT}

The authors wish to acknowledge the National Natural Science Foundation of China (grant number 11674076) for financial support provided for this research.

\section{REFERENCES}

1 Peat, K. S. A numerical decoupling analysis of perforated pipe silencer elements, Journal of Sound and Vibration, 123 (2), 199-212, (1988). https://dx.doi.org/10.1016/S0022-460X(88)80106-8

2 Gogate, G. R. and Munjal, M. L. Analytical and experimental aeroacoustic studies of open-ended three-duct per- 
forated elements used in mufflers, Journal of the Acoustical Society of America, 97 (5), 2919-2927, (1995). https://dx.doi.org/10.1121/1.411858

${ }^{3}$ Munjal, M. L. Analysis of a flush-tube three-pass perforated element muffler by means of transfer matrices, International Journal of Acoustics and Vibration, 2, 63-68, (1997).

${ }^{4}$ Selamet, A, Easwaran, V., and Falkowski, A. G. Threepass mufflers with uniform perforations, Journal of the Acoustical Society of America, 105 (3), 1548-1562, (1999). https://dx.doi.org/10.1121/1.426694

${ }^{5}$ Fan, Y. and Ji, Z. Three-pass mufflers with perforated inlet/outlet tubes, Applied Acoustics, 156, 217-228, (2019). https://dx.doi.org/10.1016/j.apacoust.2019.07.018

${ }^{6}$ Dickey, N. S, Selamet, A., and Novak, J. M. Multi-pass perforated tube silencers: a computational approach, Journal of Sound and Vibration, 211 (3), 435-447, (1998). https://dx.doi.org/10.1006/jsvi.1997.1318

7 Ramya, E. and Munjal, M. L. Improved tuning of the extended concentric tube resonator for wide-band transmission loss, Noise Control Engineering Journal, 62 (4), 252263, (2014). https://dx.doi.org/10.3397/1/376225

${ }^{8}$ Mimani, A. Double-tuned short end-chamber mufflers, In: Acoustic Analysis and Design of Short Elliptical End-Chamber Mufflers, Springer, Singapore, 2021. https://dx.doi.org/10.1007/978-981-10-4828-9_4

9 Selamet, A. and Ji, Z. Diametral plane-wave analysis for short circular chambers with end offset inlet/outlet and side extended inlet/outlet, Journal of Sound and Vibration, 214 (3), 580-587, (1998). https://dx.doi.org/10.1006/jsvi.1998.1568

${ }^{10}$ Selamet, A. and Denia, F. D. Acoustic behavior of short elliptical chambers with end central inlet and end offset or side outlet, Journal of Sound and Vibration, 245 (5), 953959, (2001). https://dx.doi.org/10.1006/jsvi.2000.3566

$11 \mathrm{Ji}, \mathrm{Z}$. and Fang, Z. Three-pass perforated tube muffler with end-resonator, SAE International Journal of Passenger Cars-Mechanical Systems, 4 (2), 989-999, (2011). https://dx.doi.org/10.4271/2011-01-1529

12 Torregrosa, A. J., Broatch, A., and Payri, R. A study of the influence of mean flow on the acoustic performance of Herschel-Quincke tubes, Journal of the Acoustical Society of America, 107 (4), 1874-1879, (2000). https://dx.doi.org/10.1121/1.428468

${ }^{13}$ Kirby, R. Transmission loss prediction for dissipative silencers of arbitrary cross section in the presence of mean flow, Journal of the Acoustical Society of America, 114 (1), 200-209, (2003). https://dx.doi.org/10.1121/1.1582448

14 Albelda, J., Denia, F. D., Fuenmayor, F. J., and Martinez, M. J. A transversal substructuring modal method for the acoustic analysis of dissipative mufflers with mean flow, Journal of the Acoustical Society of America, 123 (5), 3534, (2008). https://dx.doi.org/10.1121/1.2934497
15 Kirby, R. A comparison between analytic and numerical methods for modeling automotive dissipative silencers with mean flow, Journal of Sound and Vibration, 325 (3), 565582, (2009). https://dx.doi.org/10.1016/j.jsv.2009.03.032

${ }^{16}$ Elnady, T., Abom, M., and Allam, S. Modeling perforates in mufflers using two-ports, Journal of Vibration and Acoustics, 132 (6), 061010, (2010). https://dx.doi.org/10.1115/1.4001510

17 Lato, T. and Mohany, A. Passive damping of pressure pulsations in pipelines using Herschel-Quincke tubes, Journal of Sound and Vibration, 448 (26), 160-177, (2019). https://dx.doi.org/10.1016/j.jsv.2019.02.020

${ }^{18} \mathrm{Kang}, \mathrm{Z}$. and $\mathrm{Ji}$, Z. Acoustic length correction of duct extension into a cylindrical chamber, Journal of Sound and Vibration, 310 (4-5), 782-791, (2008). https://dx.doi.org/10.1016/j.jsv.2007.11.005

19 Chen, Z., Ji, Z., and Huang, H. Acoustic impedance of perforated plates in the presence of fully developed grazing flow, Journal of Sound and Vibration, 485, 115547, (2020). https://dx.doi.org/10.1016/j.jsv.2020.115547

${ }^{20}$ Melling, T. H. The acoustic impedance of perforates at medium and high sound pressure levels, Journal of Sound and Vibration, 29 (1), 1-65, (1973). https://dx.doi.org/10.1016/S0022-460X(73)80125-7

${ }^{21}$ Ingard, U. and Bolt, R. Absorption characteristics of acoustic material with perforated facing, Journal of the Acoustical Society of America, 23 (5), 533-540, (1951). https://dx.doi.org/10.1121/1.1906799

22 Kirby, R. and Cummings, A. The impedance of perforated plates subjected to grazing gas flow and backed by porous media, Journal of Sound and Vibration, 217 (4), 619-636, (1998). https://dx.doi.org/10.1006/jsvi.1998.1811

${ }^{23}$ Chen, Z., Ji, Z., and Huang, H. Acoustic impedance of perforated plates in the presence of bias flow, Journal of Sound and Vibration, 446, 159-175, (2019). https://dx.doi.org/10.1016/j.jsv.2019.01.031

${ }^{24}$ Sun, X., Jing, X., Zhang, H., and Shi, Y. Effect of grazingbias flow interaction on acoustic impedance of perforated plates, Journal of Sound and Vibration, 254 (3), 557-573, (2002). https://dx.doi.org/10.1006/jsvi.2001.4110

25 Lee, I. and Selamet, A. Acoustic impedance of perforation in contact with fibrous material, Journal of the Acoustical Society of America, 119 (5), 2785-2797, (2006). https://dx.doi.org/10.1121/1.2188354

${ }^{26}$ Munjal, M. L. Acoustics of Ducts and Mufflers, 2nd ed., Chapter 5, John Wiley \& Sons Ltd., Chichester, (2014). 